\title{
Importance of preserving the apex and plication of the base in left ventricular volume reduction surgery
}

Tadaaki Koyama, MD

Kazunobu Nishimura, MD, PhD

Yoshiharu Soga, MD

Oriyanhan Unimonh, MD

Koji Ueyama, MD

Masashi Komeda, MD, PhD
From the Department of Cardiovascular Surgery, Graduate School of Medicine, Kyoto University, Kyoto, Japan.

Received for publication Jan 3, 2002; revisions requested April 4, 2002; revisions received July 18, 2002; accepted for publication Aug 6, 2002.

Address for reprints: Masashi Komeda, $\mathrm{MD}, \mathrm{PhD}$, Department of Cardiovascular Surgery, Graduate School of Medicine, Kyoto University, 54 Kawahara-cho, Shogoin, Sakyo-ku, Kyoto, Japan 606-8507 (Email: masakom@kuhp.kyoto-u.ac.jp).

J Thorac Cardiovasc Surg 2003;125:669-77

Copyright $(\odot 2003$ by The American Association for Thoracic Surgery

$0022-5223 / 2003 \$ 30.00+0$

doi: $10.1067 / \mathrm{mtc} .2003 .54$
Objective: Volume reduction surgery for dilated cardiomyopathy has not yielded predictable outcomes. The purpose of this study was to clarify the efficacy of modified volume reduction surgery in preserving the left ventricular apex and reducing the left ventricular diameter at the base to maintain fiber continuity.

Methods: Heart failure was induced with propranolol in $12 \mathrm{dogs}$, and the animals were randomized into 2 groups. In one group the left ventricular wall was plicated between the 2 papillary muscles from the middle to the apex (apex-sacrificing volume reduction surgery, group $\mathrm{A}, \mathrm{n}=6$ ), and in the other group plication was done from the base to the middle (apex-sparing volume reduction surgery, group B, $\mathrm{n}=6$ ). Left ventricular function was then compared between the groups by using echocardiography and sonomicrometry crystals.

Results: After volume reduction surgery, the fractional area change at the base in group B was greater than that in group A $(40 \% \pm 3 \%$ vs $27 \% \pm 4 \%, P=.003)$. Cardiac output in group B was better than that in group A ( $2.5 \pm 0.2$ vs $1.8 \pm 0.2$ $\mathrm{L} / \mathrm{min}, P=.023)$. Left ventricular end-diastolic pressure in group $\mathrm{A}$ was higher than that in group B (16 \pm 2 vs $8 \pm 1 \mathrm{~mm} \mathrm{Hg}, P=.001)$. Fractional shortening in the long axis, as assessed by means of sonomicrometry, was better in group B than in group A.

Conclusions: Apex-sparing volume reduction surgery capable of maintaining left ventricular fiber continuity provided better left ventricular function in both the systolic and diastolic phases than apex-sacrificing volume reduction surgery in the acute heart failure model. This modification might improve the results of left ventricular volume reduction surgery.

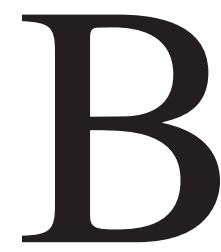

atista and colleagues ${ }^{1}$ introduced volume reduction surgery (VRS) to improve the left ventricular (LV) function of patients with dilated cardiomyopathy. The theoretic concept of this operation is that reducing the radius of the LV chamber across its short axis reduces the LV wall stress in accordance with the stress equation of Laplace:

$$
\mathrm{P}=\mathrm{k} \cdot \mathrm{T} / \mathrm{R},
$$

where $\mathrm{P}$ is the cavity pressure, $\mathrm{T}$ is the wall tension, and $\mathrm{R}$ is the radius of the chamber. Although VRS has now been performed at many institutes, operative mortality has been relatively high $(6 \%-22 \%),{ }^{1-7}$ and the results were unpredictable. VRS has been accomplished mainly by means of resection of the LV lateral free wall. The LV lateral wall has to be resected extensively from the middle to the apex to achieve adequate volume reduction, and resection of the LV apex has been 

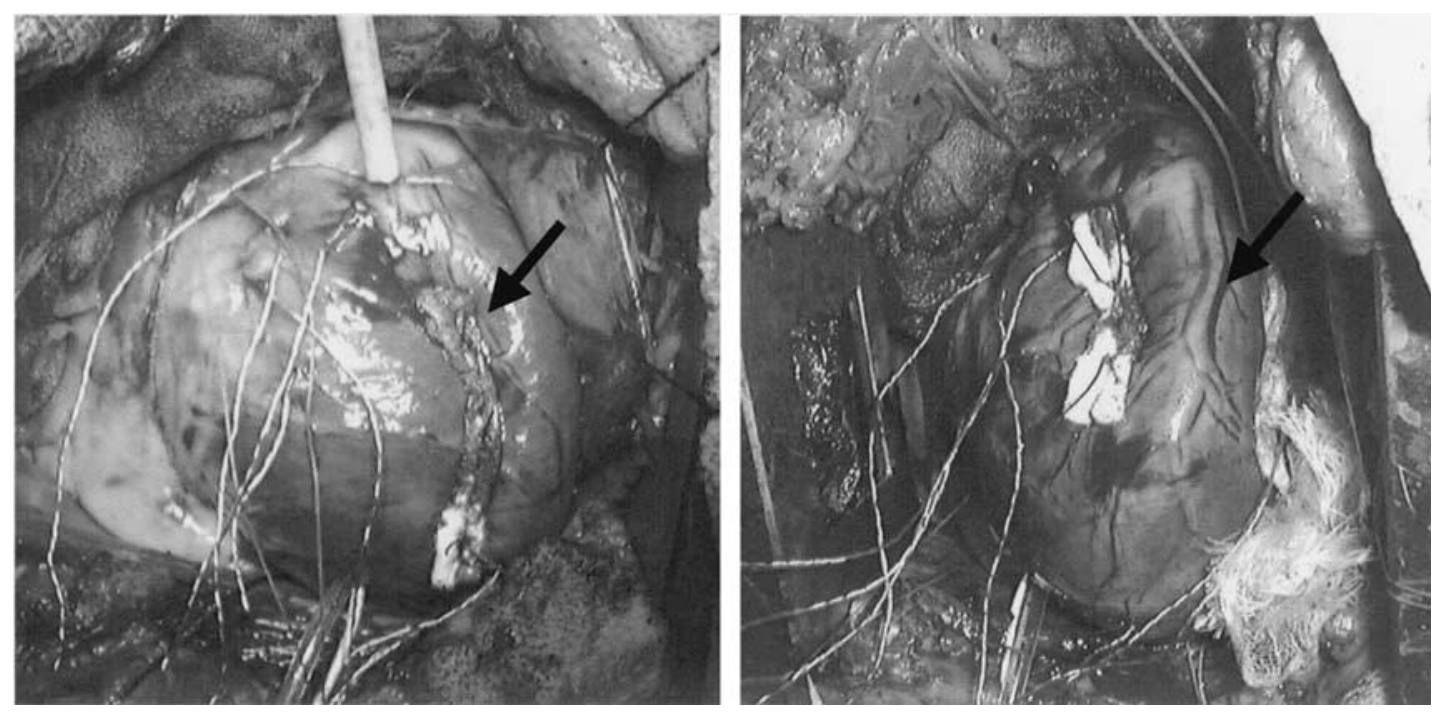

Figure 1. Intraoperative photography taken during VRS: left, apex-sacrificing VRS; right, apex-sparing VRS. Arrows show obtuse marginal branches of the circumflex coronary artery, which were left intact by the sutures.

recommended when necessary. ${ }^{1,2}$ The left ventricle is not a simple hemiovoid shape morphologically. Moreover, LV muscle fibers follow a predominantly helical course and have a 2-layer structure (epicardial side and endocardial side) that has continuity at the apex. ${ }^{8-11}$ Contraction and dilatation of the left ventricle do not involve simple symmetric motion but rather a complex dynamic motion with twist-recoil of the LV muscle fibers. Therefore conventional VRS involving resection of the LV lateral wall from the middle to the apex might compromise the continuity of the LV muscle fibers and thus impede physiologic contraction and dilatation.

We hypothesized a modification of VRS that would improve outcome by preservation of the LV apex and plication of the left ventricle at the base to maintain LV fiber continuity. The purpose of this study was to clarify the efficacy of this modified VRS (apex-sparing surgery) in comparison with conventional VRS (apex-sacrificing surgery) in dogs with experimentally induced acute heart failure.

\section{Methods}

\section{Experimental Preparation}

Twelve adult mongrel dogs weighing 15 to $22 \mathrm{~kg}$ were used. The dogs were premedicated with an intramuscular injection of 20 $\mathrm{mg} / \mathrm{kg}$ ketamine hydrochloride, and general anesthesia was induced with an intravenous injection of 10 to $15 \mathrm{mg} / \mathrm{kg}$ sodium pentobarbital. Anesthesia was maintained after endotracheal intubation with oxygen and isoflurane (0.5\%-1.5\%). A 7F CritiCath thermodilution catheter (Ohmeda, Singapore, China) was inserted into the pulmonary artery through the right external femoral vein. Cardiac output (CO) was measured by using the thermodilution technique. The dogs were placed in the right lateral decubitus position, and a left anterior thoracotomy was made through the fifth intercostal space. The pericardium was opened, and the heart was suspended in a cradle. A disposable microtipped catheter (Millar Instruments Inc, Houston, Tex) for measurement of LV pressure was directly inserted into the LV cavity from the anterior wall. Seven 2.3-mm sonomicrometry crystals (Sonometrics Corp, London, Ontario, Canada) were then inserted into the subendocardial area of the LV wall from the epicardial side.

\section{Induction of Heart Failure and VRS}

Acute congestive heart failure was induced by means of intravenous infusion of $7 \mathrm{mg} / \mathrm{kg}$ propranolol ( $\mathrm{dl}$-Propranolol Hydrochloride; Wako, Osaka, Japan). ${ }^{12}$ The 12 dogs were then randomly assigned to one of 2 groups. In one group VRS was performed with plication between the papillary muscles from the middle to the apex of the LV wall (apex-sacrificing VRS, group A, $\mathrm{n}=6$ ); in the other group VRS was performed with plication between the papillary muscles from the base to the middle (apex-sparing VRS, group $\mathrm{B}, \mathrm{n}=6$ ). The location of each papillary muscle was confirmed by using epicardial echocardiography. VRS was accomplished with 2 interrupted, horizontal 2-0 Ethibond mattress sutures (Ethicon, Inc, Somerville, NJ) with 2 strips of Teflon felt without cardiopulmonary bypass assistance (Figures 1 and 2). The sutures were placed to the LV wall adjacent to the base of each papillary muscle at the middle plane by means of epicardial echocardiography. The distance of the mattress suture was almost the same from the middle to the base or from the middle to the apex. We confirmed that 2 papillary muscles closed each other after VRS by using epicardial echocardiography. LV function was compared between the 2 groups at baseline, after induction of acute heart failure, and after VRS. All the animals received humane care in compliance with the "Principles of Laboratory Animal Care" formulated by the National Society for Medical Research and the "Guide for the Care and Use of Laboratory Animals" prepared by the Institute of Laboratory Animal Re- 

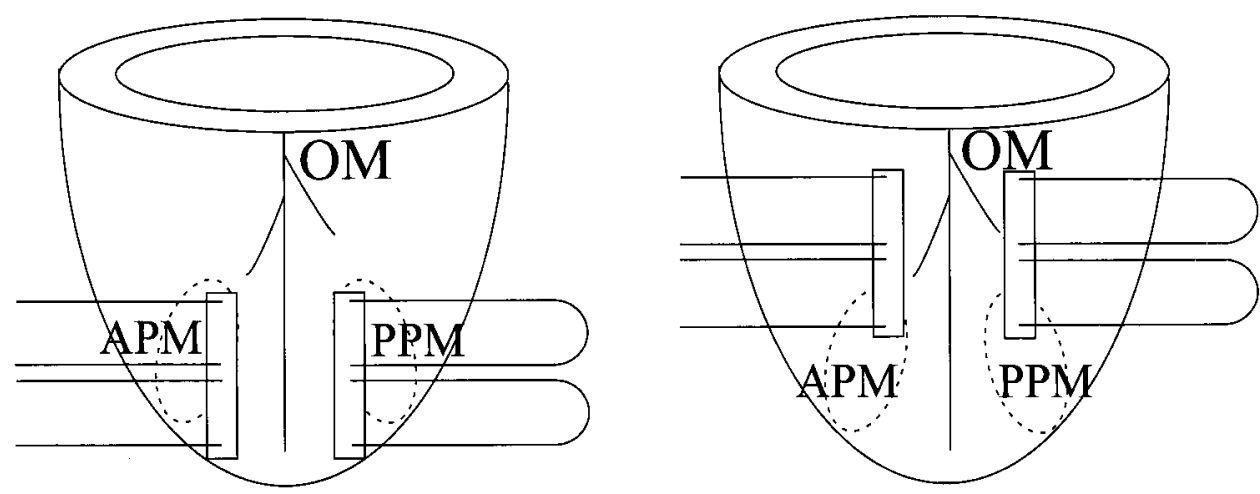

Figure 2. Schematic diagrams of the suture position with split felts in apex-sacrificing VRS (/eft, group A) and in apex-sparing VRS (right, group B). OM, Obtuse marginal; APM, anterior papillary muscle; PPM, posterior papillary muscle.

sources, National Research Council, and published by the National Academy Press (revised 1996).

\section{Cardiac Hemodynamics}

The hemodynamic parameters measured were heart rate (HR), LV systolic pressure (LVSP), LV end-diastolic pressure (LVEDP), stroke volume (SV), and CO.

\section{Epicardial Echocardiography}

LV contractility across the short axis was evaluated by means of echocardiography. After pericardiotomy, echocardiographic images were acquired by using a 7-MHZ transducer with a Toshiba SSH-260A ultrasound system (Toshiba Medical, Inc, Tokyo, Japan). After covering the transducer with a nylon pouch containing a filling gel, the echocardiographic image was obtained by placing the probe in contact with the surface of the heart. Epicardial echocardiography across the short axis was acquired at the basal, middle, and apical planes. The parameters measured were the LV diastolic dimension (LVDd), LV systolic dimension, and fractional area change (FAC). Echocardiographic images were analyzed by 2 researchers, but documenting of that image analysis was not blinded.

\section{Sonomicrometry Crystals}

Crystals $2.3 \mathrm{~mm}$ in diameter were placed on the obturator of a plastic sheath and inserted through a stab wound on the epicardial surface. The obturator was advanced into the subendocardium and then withdrawn, leaving the crystals in place. Seven crystals were arrayed at the anterior, lateral, posterior, and septal wall and apex (Figure 3). The dimension between the crystal at the apex and each of the crystals at the other locations was measured with SonoSOFT software (Sonometrics Corp) to evaluate fractional shortening (FS) in the long axis. FS was calculated from end-diastolic dimension (EDD) and end-systolic dimension (ESD):

$$
\mathrm{FS}=([\mathrm{EDD}-\mathrm{ESD}] / \mathrm{EDD}) \times 100 .
$$

\section{Statistical Analysis}

All statistical analyses were carried out by using Stat View software, version 5.0. The data are expressed as means \pm SE. Comparisons between the 2 groups were performed by using the unpaired $t$ test, and comparison of the data at each of the measurement points (baseline, after induction of acute heart failure, and after VRS) in each group were performed by using the paired $t$ test.

\section{Results}

\section{Acute Congestive Heart Failure}

Mitral regurgitation was not detected before and after induction of acute heart failure in any dogs with epicardial echocardiography. The hemodynamic variables in all dogs at baseline and after induction of heart failure are shown in Table 1. FAC in all planes decreased after induction of heart failure. LVDd across the short axis in the base and the middle plane increased after induction of heart failure. HR and LVSP decreased. LVEDP increased from $5 \pm 1$ to $8 \pm$ $1 \mathrm{~mm} \mathrm{Hg}(P<.001)$. CO and SV decreased from $2.7 \pm 0.1$ to $1.9 \pm 0.1 \mathrm{~L} / \mathrm{min}(P<.001)$ and $23 \pm 1$ to $19 \pm 2 \mathrm{~mL}$ $(P=.015)$, respectively. FS in the long axis decreased for all pairs of crystals after induction of acute heart failure (Table 2).

\section{Hemodynamics After VRS}

The results of the 2 groups during heart failure and after VRS are listed in Table 3. There were no significant differences in any of the variables between the 2 groups at the time of heart failure. After VRS, no differences were observed in HR and LVSP between the 2 groups. LVEDP in group A after VRS was markedly higher than that in group $\mathrm{B}(16 \pm 2$ vs $8 \pm 1 \mathrm{~mm} \mathrm{Hg}, P=.001)$. Although $\mathrm{SV}$ in group B was better than that in group $\mathrm{A}$, the difference was not significant ( $22 \pm 1$ vs $18 \pm 2 \mathrm{~mL}, P=.211$ ), but $\mathrm{SV}$ in 


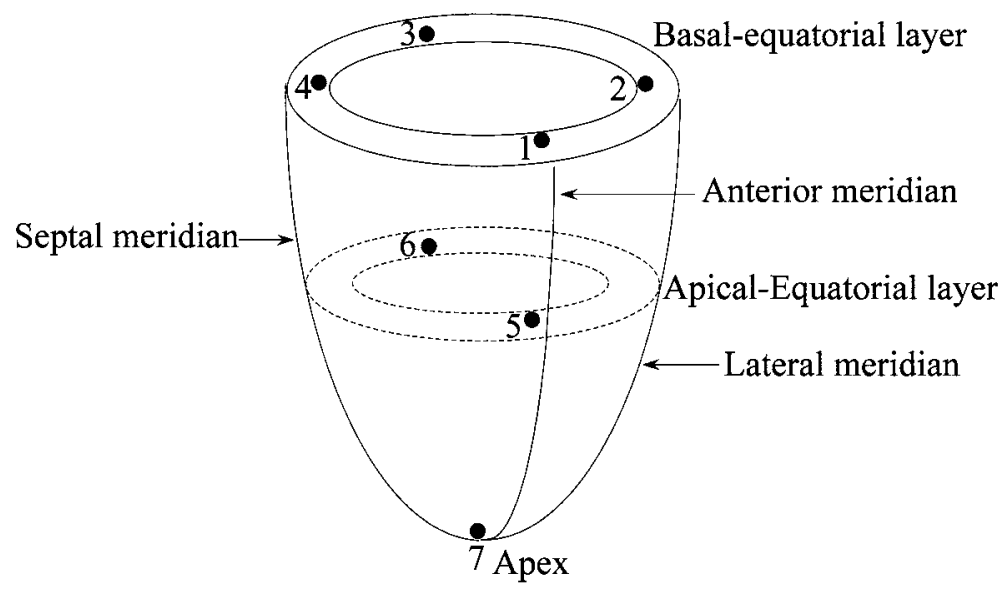

Figure 3. Location of the crystal array on the left ventricle. Filled circles represent sonomicometer crystals (2.3 $\mathrm{mm})$.

TABLE 1. Hemodynamic and epicardial echocardiographic variables in 12 dogs

\begin{tabular}{lccr}
\hline & Baseline & Heart failure & $P$ value \\
\hline Hemodynamics & & & \\
HR (beats/min) & $118 \pm 5$ & $101 \pm 3$ & $<.001$ \\
LVSP (mm Hg) & $100 \pm 4$ & $79 \pm 3$ & $<.001$ \\
LVEDP (mm Hg) & $5 \pm 1$ & $8 \pm 1$ & $<.001$ \\
SV (mL) & $23 \pm 1$ & $19 \pm 2$ & .015 \\
CO (L/min) & $2.7 \pm 0.1$ & $1.9 \pm 0.1$ & $<.001$ \\
Epicardial echocardiography at the base & & \\
LVDd (mm) & $32.4 \pm 0.7$ & $34.3 \pm 0.8$ & $<.001$ \\
LVDs (mm) & $23.7 \pm 0.7$ & $28.8 \pm 0.9$ & $<.001$ \\
FAC (\%) & $38 \pm 2$ & $23 \pm 2$ & $<.001$ \\
Epicardial echocardiography at the middle & & \\
LVDd (mm) & $34.6 \pm 0.7$ & $37.1 \pm 0.6$ & $<.001$ \\
LVDs (mm) & $23.7 \pm 0.7$ & $30.4 \pm 0.6$ & $<.001$ \\
FAC (\%) & $55 \pm 3$ & $35 \pm 3$ & $<.001$ \\
Epicardial echocardiography at the apex & & \\
LVDd (mm) & $25.7 \pm 0.5$ & $27.4 \pm 1.2$ & .136 \\
LVDs (mm) & $14.4 \pm 1.1$ & $20.5 \pm 1.5$ & $<.001$ \\
FAC (\%) & $66 \pm 4$ & $45 \pm 4$ & $<.001$ \\
\hline
\end{tabular}

LVDs, LV systolic dimension; LVSP, LV systolic pressure; LVEDP, LV enddiastolic pressure; LVDd, LV diastolic dimension.

group B increased after VRS in comparison with that before VRS $(P=.015)$, and CO in group B was better than that in group A $(2.5 \pm 0.2$ vs $1.8 \pm 0.2 \mathrm{~L} / \mathrm{min}, P=.023)$.

\section{Epicardial Echocardiography}

There were no differences in any of the parameters between the 2 groups before VRS (Table 4). After VRS, LVDd at the base in group B was smaller than that in group A (29.8 \pm 1.5 vs $34.3 \pm 1.1 \mathrm{~mm}, P=.033$ ), whereas LVDd at the apex in group A was smaller than that in group B (21.2 \pm 1.4 vs $26.6 \pm 1.3 \mathrm{~mm}, P=.017)$. There was no difference in LVDd at the middle between the 2 groups. FAC in the
TABLE 2. Fractional shortening between the crystal placed at the apex and the crystals at the other locations, as assessed by means of sonomicrometry in 12 dogs

\begin{tabular}{cccr}
\hline & Baseline (\%) & Heart failure (\%) & $\boldsymbol{P}$ value \\
\hline Crystal position & & & \\
$1-7$ & $9.2 \pm 0.9$ & $6.0 \pm 0.5$ & $<.001$ \\
$2-7$ & $10.3 \pm 0.8$ & $6.9 \pm 0.8$ & $<.001$ \\
$3-7$ & $11.7 \pm 1.0$ & $8.6 \pm 2$ & $<.001$ \\
$4-7$ & $10.6 \pm 0.8$ & $7.4 \pm 0.9$ & .007 \\
$5-7$ & $11.0 \pm 1.1$ & $7.6 \pm 0.7$ & .001 \\
$6-7$ & $15.2 \pm 1.6$ & $12.2 \pm 1.9$ & $<.001$
\end{tabular}

The figures of crystal position from 1 to 7 are the same as those in Figure 1.

base, middle, and apical planes was better after VRS in both groups (Figure 4). FAC at the base in group B was better than that in group A $(40 \% \pm 3 \%$ vs $27 \% \pm 4 \%, P=.016)$. Middle and apical FAC in group B were better than those in group A, but there were no significant differences between the groups (Table 4). Typical short-axis images obtained by means of epicardial echocardiography of each group before and after VRS are shown in Figures 5 and 6.

\section{Sonomicrometry}

FS between the crystal at the apex and crystals at any other location determined by means of sonomicrometry at the time of heart failure was similar between the 2 groups. FS for all crystal pairs in group A decreased after VRS, whereas that in group B increased (Figure 7). FS data for the 2 groups after VRS are summarized in Table 5. After VRS, FS in group B was better at any crystal position than that in group A, except for FS between the apex and basal lateral crystals. 

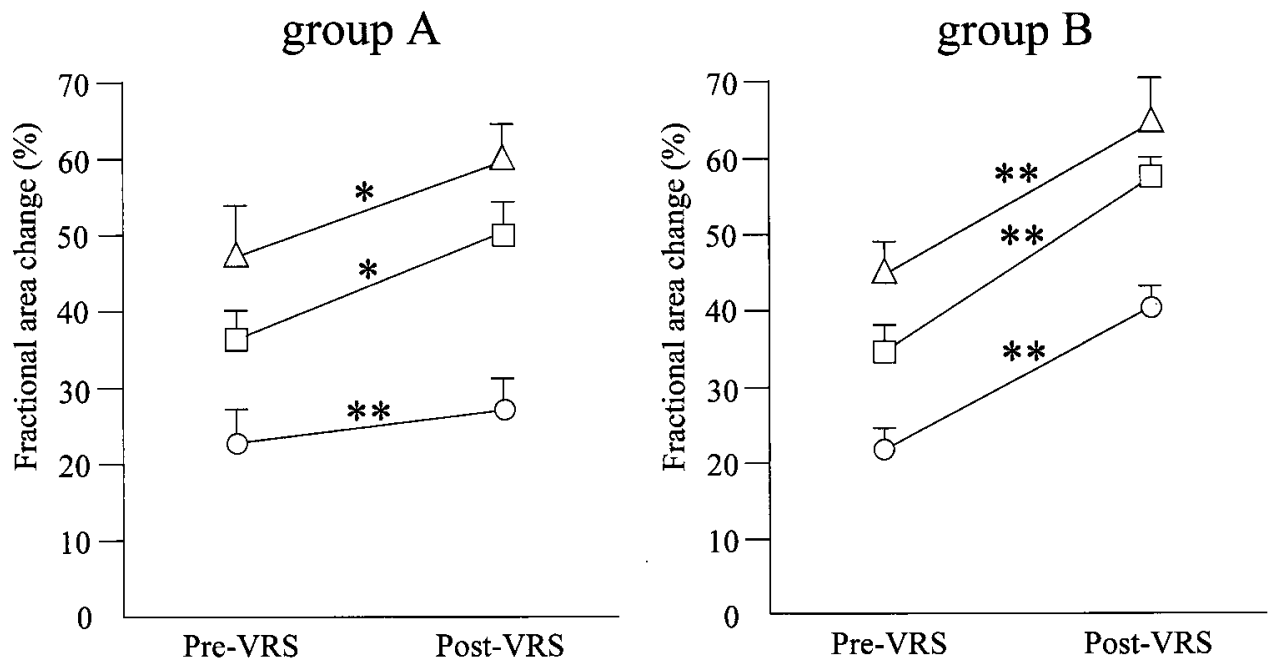

Figure 4. FAC before and after VRS. Circles indicate FAC in the basal plane. Squares show FAC in the middle plane.

Triangles indicate FAC in the apical plane. ${ }^{*} P<.05 .{ }^{*} P<.001$.

TABLE 3. Comparison of hemodynamics between 2 groups before and after VRS

\begin{tabular}{lccccrr}
\hline & \multicolumn{3}{c}{ Before VRS } & & \multicolumn{2}{c}{ After VRS } \\
\cline { 2 - 3 } & Group A & Group B & P value & & Group A & Group B \\
\hline HR (beats/min) & $94 \pm 5$ & $107 \pm 5$ & .077 & & $98 \pm 5$ & $116 \pm 7$ \\
LVSP (mm Hg) & $76 \pm 4$ & $82 \pm 4$ & .289 & & $76 \pm 5$ & .072 \\
LVEDP (mm Hg) & $8 \pm 1$ & $8 \pm 1$ & .792 & $16 \pm 2$ & .096 \\
SV (mL) & $20 \pm 3$ & $19 \pm 2$ & .726 & $18 \pm 2$ & .001 \\
CO (L/min) & $1.8 \pm 0.2$ & $2.0 \pm 0.2$ & .537 & $1.8 \pm 0.2$ & $22 \pm 1$ \\
\hline
\end{tabular}

LVSP, LV systolic pressure; LVEDP, LV end-diastolic pressure.

TABLE 4. Comparison of epicardial echocardiography between 2 groups before and after VRS

\begin{tabular}{|c|c|c|c|c|c|c|}
\hline & \multicolumn{3}{|c|}{ Before VRS } & \multicolumn{3}{|c|}{ After VRS } \\
\hline & Group A & Group B & $P$ value & Group A & Group B & $P$ value \\
\hline \multicolumn{7}{|l|}{ At the base } \\
\hline LVDd (mm) & $34.1 \pm 1.0$ & $34.6 \pm 1.3$ & .765 & $34.3 \pm 1.1$ & $29.8 \pm 1.5$ & .033 \\
\hline LVDs (mm) & $28.4 \pm 1.2$ & $29.1 \pm 1.5$ & .722 & $27.7 \pm 0.9$ & $20.7 \pm 1.3$ & .015 \\
\hline FAC $(\%)$ & $23.4 \pm 4$ & $22 \pm 2$ & .858 & $27 \pm 4$ & $40 \pm 3$ & .016 \\
\hline \multicolumn{7}{|l|}{ At the middle } \\
\hline LVDd (mm) & $36.8 \pm 0.9$ & $37.4 \pm 0.9$ & .684 & $32.2 \pm 1.2$ & $30.4 \pm 1.1$ & .297 \\
\hline LVDs (mm) & $29.7 \pm 0.7$ & $31.2 \pm 1.0$ & .278 & $24.4 \pm 1.3$ & $20.7 \pm 0.8$ & .033 \\
\hline FAC $(\%)$ & $36 \pm 4$ & $34 \pm 4$ & .734 & $50 \pm 4$ & $57 \pm 3$ & .158 \\
\hline \multicolumn{7}{|l|}{ At the apex } \\
\hline LVDd (mm) & $27.7 \pm 1.9$ & $27.1 \pm 1.6$ & .833 & $21.2 \pm 1.4$ & $26.6 \pm 1.3$ & .017 \\
\hline LVDs (mm) & $20.0 \pm 2.7$ & $21.0 \pm 1.8$ & .768 & $11.6 \pm 1.9$ & $15.2 \pm 1.2$ & .142 \\
\hline FAC $(\%)$ & $47 \pm 7$ & $44 \pm 4$ & .755 & $59 \pm 5$ & $64 \pm 4$ & .523 \\
\hline
\end{tabular}

LVDs, LV systolic dimension; LVDd, LV diastolic dimension.

\section{Discussion}

In this study we compared 2 types of VRS and evaluated systolic and diastolic LV function in dogs with experimentally induced acute heart failure. Epicardial echocardiogra- phy, which was used to observe changes in the area in the LV short axis, revealed that FAC at the LV basal level was improved after both operations but was much better after apex-sparing VRS. Sonomicrometry, which was used 

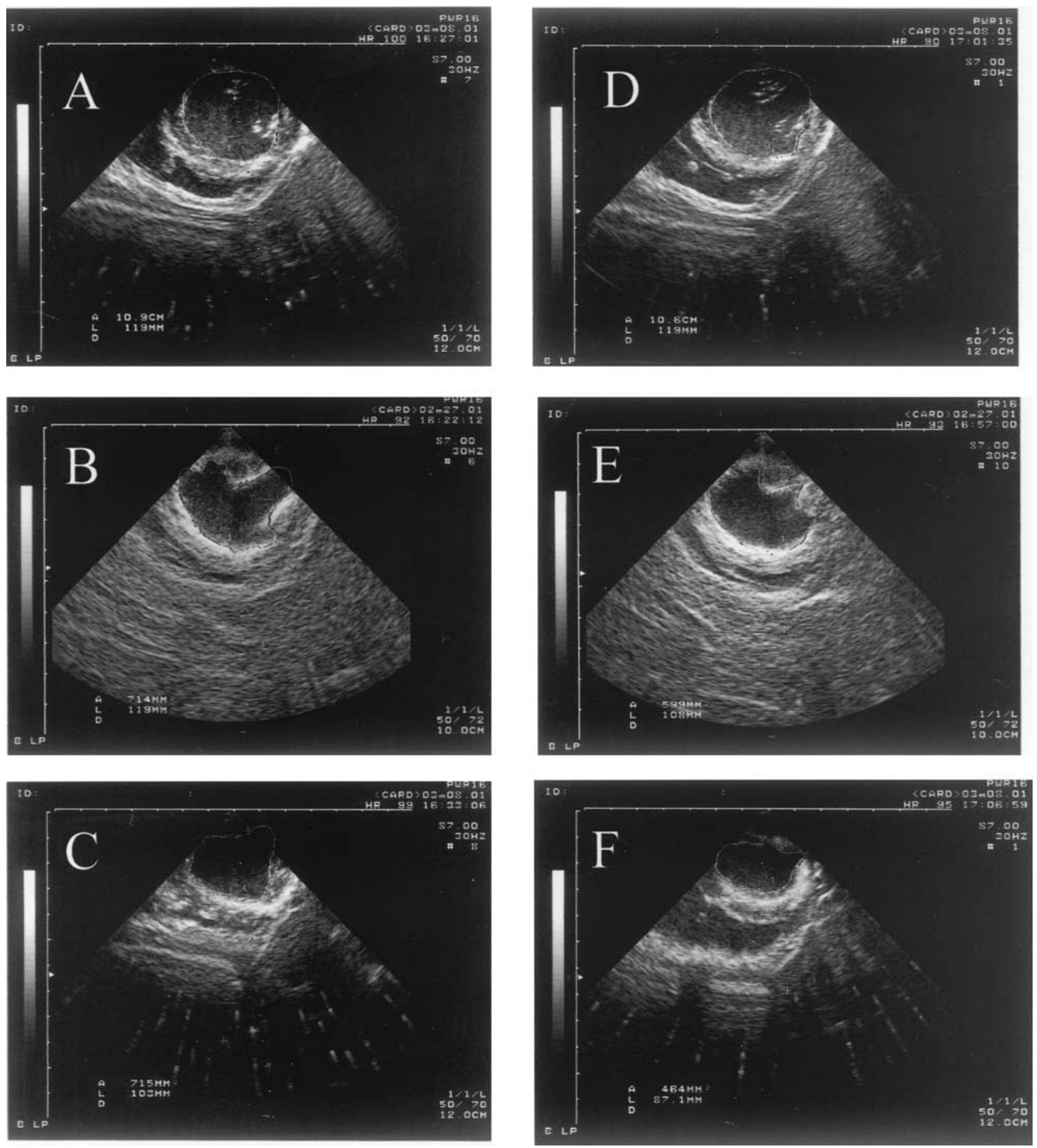

Figure 5. LV short-axis image obtained by means of epicardial echocardiography in group A: A, before VRS in the basal plane; B, before VRS in the middle plane; C, before VRS in the apical plane; D, after VRS in the basal plane; $E$, after VRS in the middle plane; F, after VRS in the apical plane.

mainly for measurement of FS along the long axis of the left ventricle, also showed that FS was improved after apexsparing VRS but not after apex-sacrificing VRS. LVEDP as a marker of diastolic function did not increase after apex- sparing VRS, whereas it increased after apex-sacrificing VRS, despite the higher $\mathrm{CO}$ obtained with apex-sparing VRS. These results indicated that a combination of LV apex sparing and basal diameter reduction was effective for im- 

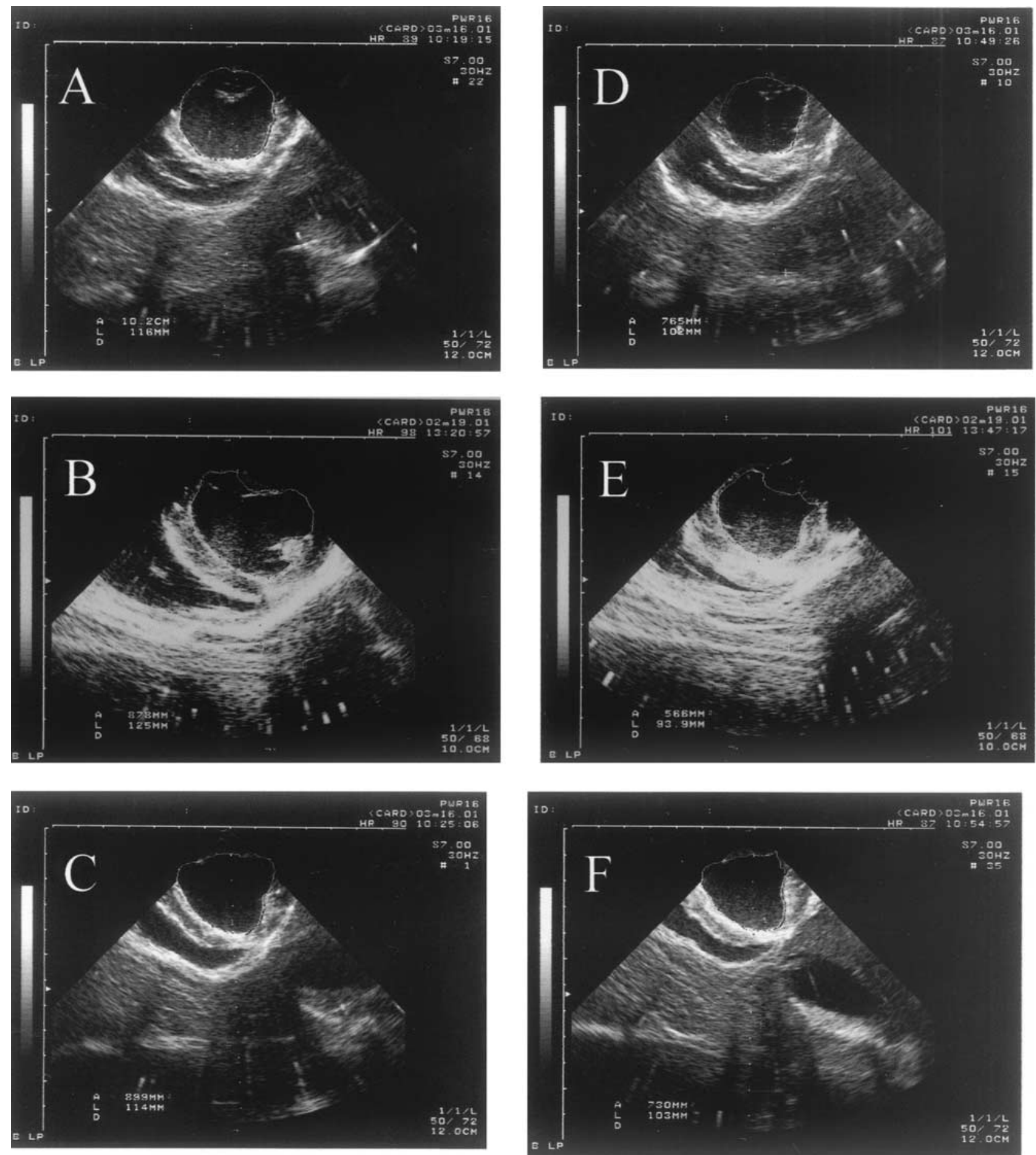

Figure 6. LV short-axis image obtained by means of epicardial echocardiography in group B: A, before VRS in the basal plane; B, before VRS in the middle plane; C, before VRS in the apical plane; D, after VRS in the basal plane; $E$, after VRS in the middle plane; $F$, after VRS in the apical plane.

provement of LV systolic and diastolic function in dogs with acute heart failure.

The LV functional benefits of VRS would be restricted when the procedure was performed between both papillary muscles from the middle to the apex. Batista and colleagues ${ }^{1}$ reported that the distance between the anterior and posterior papillary muscles limited the amount of LV resection. McCarthy and associates ${ }^{2}$ recommended transection of one or 

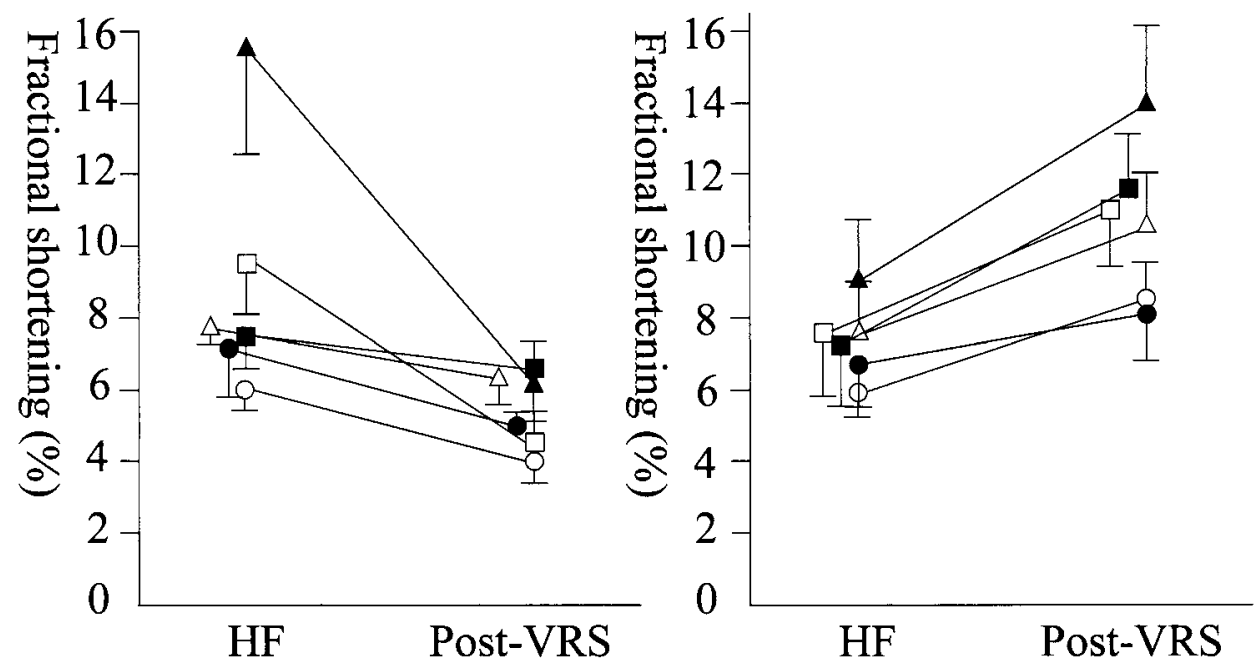

Figure 7. FS between the crystal at the apex and crystals at all other positions by means of sonomicrometry in groups A (left) and B (right). Open circles show FS between the apical and anterobasal crystals. Filled circles show FS between the apical and laterobasal crystals. Open triangles show FS between the apical and posterobasal crystals. Filled triangles show FS between the apical and septobasal crystals. Open squares show antero-middle crystals. Filled squares show postero-middle crystals. HF, Heart failure.

TABLE 5. Comparison of fractional shortening, as assessed by means of sonomicrometry after VRS

\begin{tabular}{llrl}
\hline & Group A (\%) & Group B (\%) & P value \\
\hline Crystal position & & & \\
$1-7$ & $4.0 \pm 0.6$ & $8.6 \pm 1.0$ & .003 \\
$2-7$ & $5.0 \pm 0.3$ & $8.2 \pm 1.4$ & .056 \\
$3-7$ & $4.6 \pm 0.8$ & $11.0 \pm 1.6$ & .005 \\
$4-7$ & $6.7 \pm 0.6$ & $11.6 \pm 1.5$ & .013 \\
$5-7$ & $6.3 \pm 0.7$ & $10.6 \pm 1.4$ & .023 \\
$6-7$ & $6.2 \pm 1.1$ & $13.9 \pm 2.2$ & .011 \\
\hline
\end{tabular}

The figures of crystal position from 1 to 7 are the same as those in Figure 1.

both papillary muscles and additional excision of the LV wall when necessary. Because the left ventricle is ellipsoidal, the distance between the papillary muscles gradually increases toward the LV base. Therefore reduction of the LV volume between papillary muscles would be more effective when done at the base than at the apex, without papillary muscle resection. We have found that plication of the base in apex-sparing VRS resulted in better FAC in all 3 planes (basal, middle, and apical) but especially at the base compared with that seen with apex-sacrificing VRS. Therefore our modification of VRS would enhance the benefits of VRS.

When the LV basal portion is widely resected, closure of the suture line might be difficult because of possible kinking of the main circumflex coronary artery and compromising of mitral valve function. We have previously reported successful VRS in a rat dilated cardiomyopathy model ${ }^{13}$ and confirmed that, macroscopically, plication produced the same effects as resection ${ }^{14}$ in that the 2 papillary muscles were close to each other after the operation.

Our method of VRS involving plication at the base was safer than resection, and we did not detect any mitral valve regurgitant flow or coronary event after the procedure. However, it must be borne in mind that even plication at the base should be done carefully in a clinical setting to avoid potentially fatal bleeding because of excessive tension at the suture line. In this sense the procedure would be performed more safely on an unloaded heart by using cardiopulmonary bypass. McCathy and colleagues ${ }^{15}$ reported a new concept of VRS with the Myosplint device. This device also preserves the LV apex and reduces the diameter of the middle and base of the left ventricle without muscle resection. The Myosplint might have effects hemodynamically similar to those of our apex-sparing VRS.

It has been widely known that diastolic function is impaired after VRS. LVEDP was markedly increased after apex-sacrificing VRS but not after apex-sparing VRS. Dickstein and coworkers ${ }^{16}$ reported that mass reduction caused an increase in the end-systolic elastance and ejection fraction and also an increase of diastolic chamber stiffness. They concluded that changes in systolic function were offset by changes in diastolic function, and consequently, overall pump function was decreased. Ratcliffe and associates ${ }^{17}$ reported that the effects of VRS at the apex were qualitatively similar to those of VRS performed at the lateral wall in terms of compliance, elastance, and ventricular function. However, the ventricular architecture is complex, and the angle of the LV muscle fibers is steeper at the 
apex than at the base. ${ }^{18}$ The muscle fibers have a helical architecture, and a clockwise helix predominates among the outer layers, whereas a counterclockwise helix predominates in the internal layers, and the 2 layers are continuous at the apex. ${ }^{8}$ Recently, Torrent-Guasp and colleagues ${ }^{9,10}$ described the heart to consist of a twisted band of muscle extending from the root of the pulmonary artery to the root of the aorta, and an apical loop is contributed to shortening and lengthening of the left ventricle. Apex-sacrificing VRS might have compromised the LV apical loop, and surgical intervention might result in more muscle fibers being misaligned from the original orientation. As a result, LV diastolic function might be worsened after apex-sacrificing VRS. However, in apex-sparing VRS, plication might have been done parallel to the basal loop, with little damage to the apical loop, and the integrity of the LV apex might have been preserved so that the left ventricle can easily dilate in diastole in contrast to the results of apex-sacrificing VRS. Because we did not measure the entire LV volume in this study, we are unable to draw accurate conclusion about maintaining diastolic function, but apex-sparing VRS might possibly change the previous concept of diastolic function after VRS.

This study had several limitations. First, we did not use cardiopulmonary bypass to avoid any deleterious influence it might have on the systemic circulation after VRS. The LV lateral wall was successfully plicated rather than being resected, without any harmful events. Although plication of the LV wall would presumably have the same effect as resection, there might be plication effects in the adjacent area. For example, outward plication might cause a decrease in epicardial sarcomere length and an increase in endocardial sarcomere length. As a result, the effect of the LV wall thickening during systole after outer plication would be different from that after resection, and that might have influenced the results of this study. Second, this study was conducted by using dogs with induced acute heart failure, which might differ anatomically and pathologically from chronic dilated cardiomyopathy. VRS after acute heart failure might not be the same in a chronic dilated cardiomyopathy model, in which the heart would be deformed and fibrotic. Our studies are now directed toward confirming the efficacy of apex-sparing VRS in a chronic dilated cardiomyopathy model.

In conclusion, apex-sparing VRS with LV basal plication showed better systolic and diastolic LV function than did apex-sacrificing VRS without LV basal plication in a canine model of acute heart failure, possibly by preserving the LV fiber continuity. Further investigation, especially one that uses the chronic heart failure model, would be warranted.

We thank Chikuma Hamada, PhD, Department of Pharmacoepidemiology, Kyoto University, for valuable advice about the statistical analysis.

\section{References}

1. Batista RJV, Verde J, Nery P, Bocchino L, Takeshita N, Bhayana JN, et al. Partial left ventriculectomy to treat end-stage heart disease. Ann Thorac Surg. 1997;64:634-8.

2. McCarthy PM, Starling RC, Wong J, Scalia GM, Buda T, Vargo RL, et al. Early results with partial left ventriculectomy. J Thorac Cardiovasc Surg. 1997;114:755-65.

3. Moreira LF, Stolf NAG, Bocchi EA, Bacal F, Giorgi MC, Parga JR, et al. Partial left ventriculectomy with mitral valve preservation in the treatment of patients with dilated cardiomyopathy. J Thorac Cardiovasc Surg. 1998;115:800-7.

4. Gradinac S, Miric M, Popovic Z, Popovic AD, Neskovic AN, Jovovic L, et al. Partial left ventriculectomy for idiopathic dilated cardiomyopathy: early results and six-month follow-up. Ann Thorac Surg. 1998;66:1963-8.

5. Etoch SW, Koenig SC, Laureano MA, Cerrito P, Gray LA, Dowling RD. Results after partial left ventriculectomy versus heart transplantation for idiopathic cardiomyopathy. J Thorac Cardiovasc Surg. 1999;117:952-9.

6. Suma H, Isomura T, Horii T, Sato T, Kikuchi N, Iwahashi K, et al. Nontransplant cardiac surgery for end-stage cardiomyopathy. $J$ Thorac Cardiovasc Surg. 2000;119:1233-45.

7. Franco-Cereceda A, McCarthy PM, Blackstone EH, Hoercher KJ, White JA, Youn JB, et al. Partial left ventriculectomy for dilated cardiomyopathy: is this an alternative to transplantation? J Thorac Cardiovasc Surg. 2001;121:879-93.

8. Grant RP. Notes on the muscular architecture of the left ventricle. Circulation. 1965;32:301-8.

9. Torrent-Guasp F, Whimter WF, Redmann K. A silicone rubber mould of the heart. Technol Health Care. 1997;5:13-20.

10. Torrent-Guasp F, Ballester M, Buckberg GD, Carreras F, Flotats A, Carrio I, et al. Spatial orientation of the ventricular muscle band: physiologic contribution and surgical implication. J Thorac Cardiovasc Surg. 2001;122:389-92.

11. Buckberg GD, Coghlan HC, Torrent-Guasp F. The structure and function of the helical heart and its buttress wrapping. V. Anatomic and physiologic considerations in the healthy and failing heart. Semin Thorac Cardiovasc Surg. 2001;13:358-85.

12. Soltero ER, Michael LH, Glaeser DH, Hartley CJ, Earle NR, Lawrie GM. New configuration of double cardiomyoplasty based on studies of the length-tension properties of the latissimus dorsi muscle. $J$ Thorac Cardiovasc Surg. 1993;106:842-9.

13. Yuasa S, Nishina T, Nishimura K, Miwa S, Ikeda T, Hanyu M, et al. A rat model of dilated cardiomyopathy to investigated partial left ventriculectomy. J Card Surg. 2001;16:40-7.

14. Nishina T, Nishimura K, Yuasa S, Miwa S, Nomoto T, Sakakibara Y, et al. Initial effects of the left ventricular repair by plication may not last long in a rat ischemic cardiomyopathy model. Circulation. 2001; 104(suppl I):I241-5.

15. MacCathy PM, Takagaki M, Ochiai Y, Young JB, Tabata T, Shiota T, et al. Device-based change in left ventricular shape: a new concept for the treatment of dilated cardiomyopathy. J Thorac Cardiovasc Surg. 2001;122:482-90.

16. Dickstein M, Spotnitz HM, Rose EA, Burkhoff D. Heart reduction surgery: an analysis of the impact on cardiac function. J Thorac Cardiovasc Surg. 1997;113:1032-40.

17. Ratcliffe MB, Hong J, Salahieh A, Ruch S, Wallace AW. The effect of ventricular volume reduction surgery in the dilated poorly contractile left ventricle: a simple finite element analysis. $J$ Thorac Cardiovasc Surg. 1998;116:566-77.

18. Streeter DD, Spotnitz HM, Patel DP, Ross J, Sonnenblick EH. Fiber orientation in the canine left ventricle during diastole and systole. Circ Res. 1969;24:339-47. 